\title{
Médiévales
}

Langues, Textes, Histoire

50 | printemps 2006

Sociétés nordiques en politique (XII $-\mathrm{XV}^{\mathrm{e}}$ siècles)

\section{Avertissement au lecteur}

\section{(2) OpenEdition}

1 Journals

Édition électronique

URL : https://journals.openedition.org/medievales/1327

DOI : $10.4000 /$ medievales. 1327

ISSN : 1777-5892

Éditeur

Presses universitaires de Vincennes

\section{Édition imprimée}

Date de publication : 1 juin 2006

Pagination : 1-2

ISBN : 2-84292-186-0

ISSN : 0751-2708

Référence électronique

«Avertissement au lecteur », Médiévales [En ligne], 50 I printemps 2006, mis en ligne le 09 février 2007, consulté le 24 avril 2022. URL : http://journals.openedition.org/medievales/1327 ; DOI : https://

doi.org/10.4000/medievales. 1327

Ce document a été généré automatiquement le 24 avril 2022

Tous droits réservés 


\section{Avertissement au lecteur}

1 Depuis le début de cette année, Médiévales est consultable en ligne sur le site de Revues.org ${ }^{1}$. Les « internautes »-comme il est d'usage de le dire - ont désormais accès aux introductions, résumés et comptes rendus des numéros récents et au texte intégral des articles parus depuis plus de deux ans. À nos lecteurs et abonnés je me devais de dépeindre la philosophie qui préside à ce nouveau développement de la revue.

2 Il convient tout d'abord de préciser que cette opération a débuté avant que le CNRS n'engage une politique fortement incitative en matière de publication électronique des revues de sciences humaines et sociales. Du reste, Médiévales a fait partie des rares revues d'histoire médiévale à voir reconduite telle quelle sa subvention - au terme d'un examen qui a démontré son audience internationale. Si nous avons décidé, il y a maintenant deux ans, de mettre en place une version électronique, ce ne fut donc pas par nécessité mais par choix.

3 Dans le paysage encore assez pauvre des revues électroniques, il nous semble que Médiévales peut jouer un rôle de référence en matière de "médiévistique ». Les dossiers thématiques qui traduisent les avancées les plus récentes de la recherche, les débats sur des ouvrages de premier plan, les comptes rendus qui enregistrent avec rapidité les apports des nouvelles publications: tout ce qui fait la spécificité de la revue est susceptible d'intéresser, croyons-nous, de nouveaux lecteurs qui, familiers d'Internet, n'ont peut-être pas eu encore l'occasion de la rencontrer dans les rayonnages des bibliothèques ou des librairies qu'ils fréquentent - notamment à l'étranger. C'est pour assurer cet élargissement du lectorat que nous avons choisi de travailler avec la plateforme Revues.org, qui offre le double avantage d'un excellent signalement dans les principaux moteurs de recherches et d'une grande facilité de consultation grâce au format html.

4 Nous sommes donc persuadés que la publication en ligne, loin d'être une concurrente pour l'édition sur papier, peut aider au développement de celle-ci. Les premiers résultats confirment pleinement notre analyse; grâce à ce nouveau support, nous avons d'ailleurs gagné non seulement des lecteurs mais des auteurs qui, entraînés par le contenu de la revue et encouragés par les procédures de soumission en ligne que nous avons instituées, nous ont envoyé des articles. 
5 Dans la longue phase de préparation de la mise en ligne, nous avons bénéficié de l'appui constant de notre éditeur, les Presses Universitaires de Vincennes, qui n'a pas cédé aux sirènes d'une frilosité commerciale à courte vue. La jeune équipe de Revues.org a réussi avec dynamisme et professionnalisme à régler les nombreux problèmes techniques qui accompagnent le passage d'une édition papier à une édition électronique. Tous ces efforts ont été coordonnés de main de maître par Didier Boisseuil, qui continuera à être le responsable de Médiévales en ligne. N'hésitez pas à lui adresser vos remarques ou vos souhaits concernant l'ergonomie ou le contenu du site, ou encore sur les développements qu'il convient de lui donner ${ }^{2}$.

6 Nous sommes parfaitement conscients de tout ce qu'il reste à faire. Un index raisonné de tous les articles parus dans Médiévales depuis sa création sera prochainement mis en ligne - ce qui doit amener à s'interroger sur la numérisation des numéros anciens, et singulièrement des numéros épuisés. D'autres développements sont à l'étude. C'est donc bien un champ prometteur qui s'ouvre pour notre revue.

\section{NOTES}

1. http://www.revues.org

2. didier.boisseuil@univ-avignon.fr 